Eyvind Elstad

Universitetet i Oslo

Knut-Andreas Christophersen

Universitetet i Oslo

DOI: http://dx.doi.org/10.5617/adno.3589

\title{
Læreres kollegiale hjelpsomhet med IKT i undervisning og deres forbedringsbestrebelser
}

\section{Sammendrag}

Denne studien undersøker hvilke organisasjonsmessige faktorer som er relatert til lareres kollegiale hjelpsomhet med IKT $i$ undervisning og lareres forbedringsbestrebelser. Analysen baseres seg på et utvalg av larere i videregående skoler som plasserer seg i midtsjiktet når det gjelder inntakspoeng og bidrag til elevers leringsframgang. Det anvendes tversnittsanalyse, og strukturell likningsmodellering er brukt som metode. Vi finner at tydelig kommunisert ledelse er relatert til lareres kollegiale hjelpsomhet med IKT i undervisning. Derimot finner vi noe svakere sammenheng mellom tydelig ledelse og lareres forbedringsbestrebelser og utviklingsorientert skolekultur. Et annet funn er en noe svak, men negativ relasjon mellom utviklingsorientert skolekultur og læereres individuelle forbedringsbestrebelser. Vi drøfter dette funnet som opplagt bør følges opp i videre forskning. Relasjonell tillit mellom lcerere er derimot svakt relatert til både kollegial hjelpsomhet og individuelle forbedringsbestrebelser. Men det er en moderat sterk relasjon mellom tydelig ledelse og utviklingsorientert skolekultur på den ene siden og tydelig ledelse og kollegial tillit mellom lcerere på den andre siden. Dette indikerer at tydelig kommunisert ledelse er relatert til både skoleutvikling, kollegial tillit og kollegial hjelpsomhet. Vi finner en meget svak sammenheng mellom utviklingsorientert skolekultur og kollegial hjelpsomhet. Implikasjoner for videre forskning drøftes.

Nøkkelord: IKT, lcerere, kollegial hjelpsomhet, individuelle forbedringsbestrebelser, tydelig ledelse, skolekultur, relasjonell tillit

\section{Teachers’ organizational citizenship behavior for ICT in teaching and their improvement efforts}

\section{Abstract}

This study investigates organizational factors related to teachers' organizational citizenship behavior for ICT in teaching and their improvement efforts. 
The analysis is based on a sample of high school teachers working at schools characterized by near average intake points and value added measures. The method used is a cross-sectional analysis and structural equation modelling. We find that clear leadership is related to teachers' organizational citizenship behavior for ICT in teaching. We find a weaker relation between clear leadership and teachers' improvement efforts and a development-oriented school culture. Another finding is a weak, but negative relation between developmentoriented school culture and teachers' individual improvement efforts. We discuss this finding which should be an avenue for further research. Relational trust among teachers is weakly related to both organizational citizenship behavior and individual improvement efforts. But to a certain extent, there is a strong and a moderately strong association between clear leadership and development-oriented school culture on the one hand and clear leadership and organizational citizenship behavior on the other hand. These relations indicate that clear leadership is related to school development projects, relational trust among school professionals and organizational citizenship behavior. We find a very weak association between development-oriented school culture and organizational citizenship behavior. Implications for further research are discussed.

Keywords: ICT, teachers, organizational citizenship behavior, improvement efforts, clear leadership, school culture, relational trust

\section{Introduksjon}

Denne artikkelen handler om faktorer som er relatert til læreres hjelpsomhet og forbedringsbestrebelser i en tid der det foregår store satsinger på å ta i bruk informasjons- og kommunikasjonsteknologi (IKT) i skolens undervisning. Vi forstår forbedringsbestrebelser som «those conscious and planned activities which are intended to be of direct benefit to the individual, group or school and which contribute, through these, to the quality of education in the classroom» (de Vries, Jansen \& van de Grift, 2013, s. 79). Forbedringsbestrebelser omfatter altså arbeid der lærerne - enten alene eller sammen med andre - føler en forpliktelse til å reflektere over egen og andres undervisningspraksis (inkludert planlegging av og etterarbeid av undervisning).

I denne artikkelen retter vi vår oppmerksomhet mot individuelle forbedringsbestrebelser hos lærere. I regjeringens strateginotat Lærerløftet heter det at lærere må kunne undervise med digitale verktøy og integrere digital kompetanse som en av de fem grunnleggende ferdighetene (Kunnskapsdepartmentet, 2014). Regjeringens satsinger på IKT i undervisning har gitt en rekke nye utfordringer for skoler. Det er faglig interessant å studere hvordan organisasjonsmessige faktorer i skolen er relatert til læreres motivasjon for å hjelpe kollegaer og forbedre sin egen undervisning. Derfor er det interessant å studere organisasjonsmessige 
faktorer i en tidsalder som betoner omstilling i skolen i retning av å ta i bruk digitale hjelpemidler i undervisningen (Elstad, 2016a). Kollegial hjelpsomhet med IKT i undervisning er et aspekt som det fokuseres på i denne artikkelen ved siden av den individuelle lærers forbedringsbestrebelser i sitt arbeid (der mestring av IKT i undervisning er bare ett av flere momenter). Med kollegial hjelpsomhet menes her «behavior that contributes indirectly to the organization through the maintenance of the organization's social system» (LePine, Erez \& Johnson, 2002, s. 52). Begrepene kollegial hjelpsomhet og individuelle forbedringsbestrebelser er endogene variabler $\mathrm{i}$ analysen som rapporteres $\mathrm{i}$ denne artikkelen. Spørsmålet er hva slags organisasjonsmessige faktorer som er relatert til disse to variablene. Formålet med denne undersøkelsen er å utforske faktorer som vi på teoretisk grunnlag mistenker for å være relatert til de to avhengige variablene. På den annen side kan vi ikke bevise kausalretningen. Det betyr at selv om vi opererer med eksogene og endogene variabler i modellen, holder vi det åpent hvilken vei kausalretningen går. Faktorene som vi antar er relatert til kollegial hjelpsomhet og individuelle forbedringsbestrebelser, er: skolekultur, relasjonell tillit mellom lærere, læreres relasjonelle tillit til skoleledere og læreres persepsjon av lederskap.

Ledelse i utdanningssektoren er innrettet for at skolen skal nå sine mål (Leithwood \& Riehl, 2003). Tidligere forskning har gitt belegg for å hevde at ledelse har betydning for skoleprestasjoner (Robinson, Lloyd \& Rowe, 2008). Men en organisasjon som skolen kan bare i begrenset grad styres, kontrolleres og ledes til et høyt kvalitetsnivå: kvalitet i skolen vil ikke minst være avhengig av den enkelte lærers forbedringsbestrebelser, læreres profesjonelle «commitment» og vekst (Elstad, Christophersen \& Turmo, 2011). Læreres arbeid omfatter ikke bare den individuelle lærers undervisning i klasserommet (der læreren som oftest underviser alene) og den individuelle lærers forbedringsbestrebelser, men også interaksjon med kollegaer (Kelchtermans, 2006). For eksempel kan dette skje ved at lærere hjelper andre lærere (Christ, Dick, Wagner \& Stellmacher, 2003). Det sistnevnte kalles gjerne «organisational citizenship behavior» (Organ, 1988). Her velger vi å bruke kollegial hjelpsomhet som norsk betegnelse. Denne hjelpsomheten henspiller på en medborgerplikt i skolens organisasjon, altså en slags sinnelagsetisk begrunnelse for å hjelpe andre lærere.

Artikkelen er bygd opp slik: Først redegjør vi for det teoretiske rammeverket for studien, og deretter redegjør vi for det empiriske undersøkelsesopplegget (som innbefatter strukturell likningsmodellering) og resultatene som framkommer. Dernest drøfter vi resultatene i lys av de teoretiske forventningene og drøfter implikasjoner for videre forskning. 


\section{Teoretisk rammeverk}

Det teoretiske rammeverket kombinerer flere teoretiske linser. Den første komponenten består av antakelser om at tydelig kommunisert ledelse på en skole er relatert til læreres individuelle forbedringsbestrebelser, men også deres kollegiale hjelpsomhet i spørsmålet om å ta i bruk en innovasjon i undervisning (Moolenaar, Daly \& Sleegers, 2010). Det nasjonale nivået i styringskjeden forventer at lærere underviser ved hjelp av digitale verktøy (Kunnskapsdepartementetet, 2014). Dette er et eksempel på en nasjonal styringsintensjon. Denne styringsintensjonen følges opp gjennom lederskap på forskjellige nivåer, dvs. målrettet arbeid ved en skole for at skolen skal fornye sin undervisningspraksis ved hjelp av digitale hjelpemidler (Hauge \& Lund, 2012). I videregående skole har nær sagt alle elever i dag tilgang til datamaskiner, og i noen fylker er det gitt klare føringer på at utstyret skal brukes i undervisningen (Elstad, 2016b). Læringsressurser i de fleste fag i videregående skole er tilgjengelig for alle gjennom nettportalen www.ndla.no og andre nettsteder. Noen skoler har også tilgang på annen pedagogisk programvare som er tilgjengelig gjennom forlagsavtaler o.l. Læringsmål som er nedfelt i nasjonale læreplaner, inviterer til at lærere integrerer bruk av teknologi i sin undervisning (Elstad, 2016b). Det finnes forskningsbaserte studier som gir empirisk støtte til vår forventning om at tydelig ledelse er relatert til både den individuelle læreres forbedringsbestrebelser - hypotese 1 (Moolenaar \& Sleegers, 2010; Avalos, 2011; Turmo, Elstad \& Christophersen, 2013) og kollegial hjelpsomhet - hypotese 2 (Belogolovsky \& Somech, 2010; DiPaola \& Tschannen-Moran, 2014; Elstad, Christophersen \& Turmo, 2011). Tydelig kommunisert ledelse kan oppfattes som en tautologi. Men når vi i det følgende bruker tydelig ledelse som begrep, er det for å understreke at skolens mål kommuniseres til lærerne på en måte som gjør at målene faktisk oppfattes av lærerne.

Læreres relasjonelle tillit til skoleledere blir betraktet som en viktig forutsetning for at ledelsens intenderte handlinger skal være virksomme (Bryk \& Schneider, 2002). Denne antakelsen finner sin begrunnelse i «Human Resource Management»-forskning (Kuvaas \& Dysvik, 2016), men også i skoleledelseslitteratur (Tschannen-Moran, 2014). Noen forskere sammenlikner relasjonell tillit med smøreoljen i et maskineri: relasjonell tillit har betydning for om målene som er kommunisert blir et viktig personlig mål for læreren (Bryk \& Schneider, 2002). I denne sammenheng er både relasjonell tillit mellom lærere (kollegial tillit) og læreres relasjonelle tillit til sine skoleledere påaktet. Vi antar derfor at kollegial tillit er relatert til individuelle forbedringsbestrebelser - hypotese 3 (Bryk, 2010; DiPaola \& Tschannen-Moran, 2014), og at kollegial tillit er relatert til kollegial hjelpsomhet - hypotese 4 (Zeinabadi \& Salehi, 2011; DiPaola \& Tschannen-Moran, 2014). Relasjonell tillit til skoleledere viser seg i annen forskning å være relatert til kollegial hjelpsomhet - hypotese 5 (Bryk \& Schneider 2002), og vi formoder også at tillit til ledere er positivt relatert til 
individuelle forbedringsbestrebelser - hypotese 6 (Bryk, 2010; Daly, Moolenaar, Bolivar \& Burke, 2010).

Kulturen på en arbeidsplass gjør seg gjeldende blant annet gjennom de sosiale normene som eksisterer blant kollegaer (Hargreaves, 1995; DiPaola \& Tschannen-Moran, 2014). Man kan snakke om utviklingsorientert skolekultur versus en skolekultur som er preget av status quo-tenkning (Moolenaar \& Sleegers, 2010; Huberman \& Miles, 2013). Taler vi om en utviklingsorientert skolekultur, antar vi at det er utbredte sosiale normer som støtter opp om tanken om å prøve ut digitale læringsressurser i undervisning. På en videregående skole vil dette knyttes til skolefag, og utviklingsarbeidet skjer gjerne i fagseksjoner. En tilstandsorientert skolekultur kan derimot være preget av sosiale normer som ikke fremmer utprøving og nyorientering (for eksempel ved talemåter som «slik har vi alltid gjort det på denne skolen»). I forbindelse med IKT i undervisningen kan en utviklingsorientert skolekultur være gunstig for utprøving av nye løsninger (Hauge \& Lund, 2012). Dersom sosiale normer gir føringer for å prøve ut nye ideer som har med digitale læremidler å gjøre, vil det være et klima for forbedringsbestrebelser (Moolenaar, Daly \& Sleegers, 2011) - hypotese 7 - og kollegial hjelpsomhet - hypotese 8 (DiPaola \& Tschannen-Moran, 2014).

Videre antar vi at tydelig kommunisert lederskap er en organisasjonsmessig faktor som er relatert til utviklingsorientert skolekultur: hypotese 9 (som understøttes av Moolenaar, Daly \& Sleegers, 2010). Dessuten antar vi at kollegial tillit mellom lærere er gunstig for et utviklingsorientert skoleklima: hypotese 10 (som understøttes av Moolenaar \& Sleegers, 2010). I det sistnevnte tilfellet antar vi at relasjonen mellom kollegial tillit og relasjonell tillit til skoleledere er forbundet, men vi tør ikke ha noen formening om entydig kausalretning. Vi antyder dette i figur 1 som toveis relasjon. Det finnes forskning (Tschannen-Moran, 2014) som underbygger at relasjonell tillit til skoleledere er gunstig for å skape en utviklingsorientert skolekultur: hypotese 11.

Relasjonell tillit til ledere antar vi er relatert til persepsjonen av tydelig ledelse (Bryk \& Scheider, 2002), uten at vi her har formening om kausalretning - hypotese 12. Til slutt antar vi også at kollegial tillit er relatert til persepsjonen av tydelig ledelse (Bryk, 2010) - hypotese 13. Hypotese 14 er at vi antar at relasjonell tillit til skoleledere har sammenheng med kollegial tillit.

Hypotesene, som er plassert i figur 1, viser hvilke organisasjonsmessige faktorer vi antar er relatert til kollegial hjelpsomhet og forbedringsbestrebelser. Figur 1 viser endogene og eksogene variabler i en modell som brukes i en empirisk undersøkelse. Dermed projiserer vi inn en kausalforståelse i analysen av et datasett der vi strengt talt ikke kan bevise eller klart begrunne kausalretninger. Imidlertid krever våre analytiske verktøy en slik strategi fordi strukturell likningsmodellering forutsetter en ide om hvilke variabler som er endogene og hvilke som er eksogene. I vår tolkning av empiriske resultater åpner vi imidlertid opp for at kausalretningen er ubestemt og at relasjonene kan forstås som assosiasjoner. 

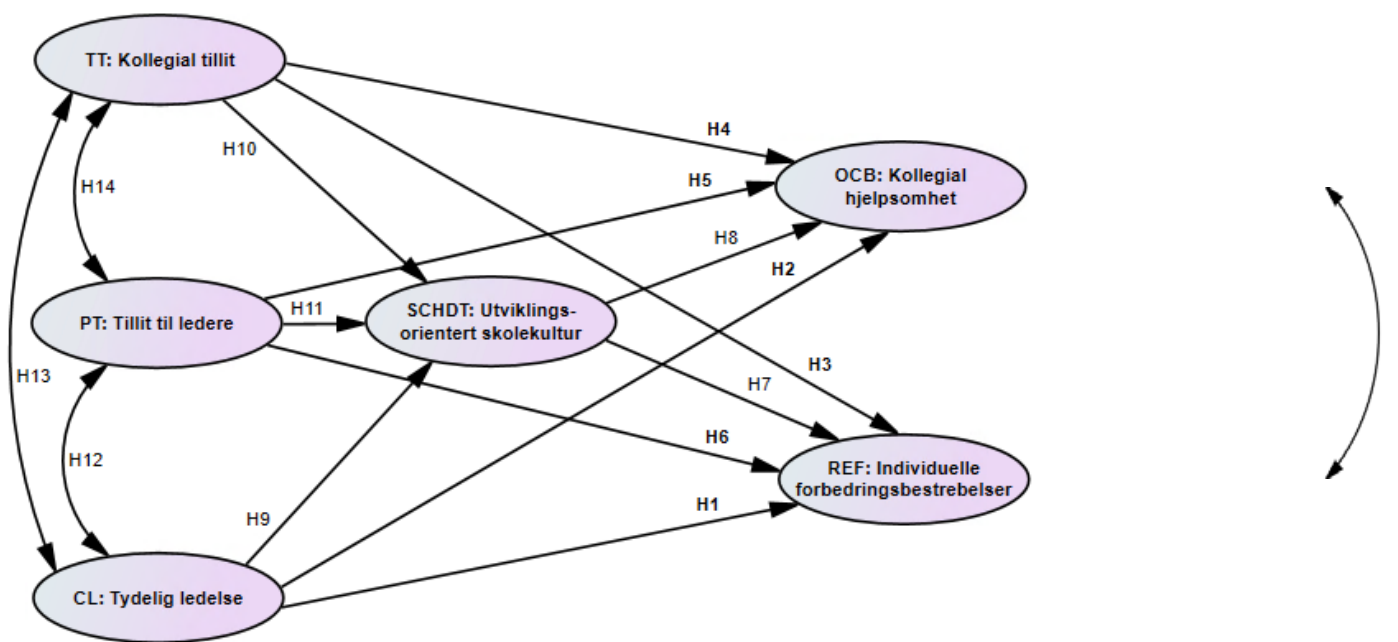

Figur 1. Teoretisk modell med teoretiske begreper, forkortelser av begreper og hypoteser om empiriske relasjoner (H1 betegner hypotese nr. 1 osv.).

\section{Gjennomføring: Utvalg, operasjonalisering og beskrivende statistikk}

For å undersøke våre hypoteser gjennomførte vi en survey blant lærere ved 3 videregående skoler i Norge. Datainnsamlingen skjedde ved en oppsøkende, papirbasert spørreskjemaundersøkelse der lærerne besvarte spørreskjemaet i forbindelse med en planleggingsdag. Fordelen ved denne metoden var at alle lærere hadde plikt til å delta på planleggingsdagen. ${ }^{1}$ Ingen lærere reserverte seg mot deltakelse. Det betyr at bortsett fra de som var fraværende på innsamlingsdagen, er utvalget vi har analysert å betrakte som tilnærmet fullstendig. Med andre ord er bortfallsskjevheten i utvalget neglisjerbar. Disse tre videregående skolene kan imidlertid ikke betraktes som representative for norske videregående skoler og deres lærere. De tre videregående skoler tilbyr det sentrale studieforberedende programmet, og de betraktes som nokså like: elevenes standpunktkarakterer fra grunnskolen ved de tre skolene var i gjennomsnitt 4.25, og også de tre videregående skolenes skolebidragsindikatorer er nokså like (i gjennomsnitt -0.35) (Falch, Bensnes \& Strøm, 2016). Med andre ord er skolene å betrakte som omtrent gjennomsnittlige når det gjelder elevenes kunnskapsgrunnlag ved oppstart og elevenes læringsframgang i løpet av skoletiden (opplysninger om elevinntak og skolebidragsindikatorer er estimert basert på årskullene 2008-2009: Falch, Bensnes \& Strøm, 2016). Denne egenskapen ved utvalget har - som vi skal komme tilbake til - betydning for de slutninger som kan trekkes.

Lærerne ble bedt om å merke av på en skala hvilket alternativ som samsvarte best med deres egen overbevisning. Dette skjedde ved at lærerne skulle ta stilling til spørsmål eller påstander som vi gjengir i det følgende (begrep med fet skrift og deretter anvendt indikator): 
Tabell 1. Begreper (fet skrift) og tilhørende indikator, beskrivende statistikk og Cronbachs alfa/ Spearman-Brown koeffisient (forkortet SB), N = 159.

\begin{tabular}{|c|c|c|c|c|c|c|}
\hline $\begin{array}{l}\text { Begreper og eksempel på } \\
\text { indikator }\end{array}$ & $\begin{array}{l}\text { Indikator } \\
\text {-nummer }\end{array}$ & $\begin{array}{l}\text { Gjennom } \\
\text {-snitt }\end{array}$ & $\begin{array}{l}\text { Standard } \\
\text {-avvik }\end{array}$ & $\begin{array}{l}\text { Skjev- } \\
\text { het }\end{array}$ & Kurtose & $\begin{array}{l}\text { Alfa / } \\
\text { SB }\end{array}$ \\
\hline $\begin{array}{l}\text { OCB: Læreres kollegiale } \\
\text { hjelpsomhet med IKT i under- } \\
\text { visning } \\
\text { Jeg hjelper uoppfordret andre } \\
\text { lærere med å finne ut av hvor- } \\
\text { dan de skal klare å ta i bruk } \\
\text { undervisningsopplegg med digi- } \\
\text { tale læremidler }\end{array}$ & w77 & 4.52 & 1.51 & -0.36 & -0.45 & $\begin{array}{l}.715 / \\
.715\end{array}$ \\
\hline $\begin{array}{l}\text { REF: Individuelle forbed- } \\
\text { ringsbestrebelser med egen } \\
\text { undervisning } \\
\text { Jeg snapper opp «gode } \\
\text { eksempler» fra andre kollegaer } \\
\text { på skolen for å forbedre egen } \\
\text { undervisning }\end{array}$ & $\begin{array}{l}\text { w108 } \\
\text { w109 }\end{array}$ & 5.99 & 1.06 & $\begin{array}{l}-1.45 \\
-0.56\end{array}$ & 3.39 & $\begin{array}{l}.715 / \\
.726\end{array}$ \\
\hline $\begin{array}{l}\text { SCHD: Utviklingsorientert } \\
\text { skolekultur } \\
\text { På min skole prøver vi alltid ut } \\
\text { nye ideer som har med digitale } \\
\text { læremidler å gjøre }\end{array}$ & $\begin{array}{l}\text { w54 } \\
\text { r55 }\end{array}$ & $\begin{array}{l}4.04 \\
5.10\end{array}$ & $\begin{array}{l}1.39 \\
1.43\end{array}$ & $\begin{array}{l}-0.27 \\
-0.77\end{array}$ & $\begin{array}{r}-0.35 \\
0.24\end{array}$ & $\begin{array}{l}.513 / \\
.514\end{array}$ \\
\hline $\begin{array}{l}\text { TT: Relasjonell tillit mellom } \\
\text { kollegaer (Bryk \& Schneider, } \\
\text { 2002) } \\
\text { Lærerne på denne skolen har } \\
\text { tillit til hverandre } \\
\end{array}$ & $\begin{array}{l}\text { w94 } \\
\text { w97 }\end{array}$ & $\begin{array}{l}5.74 \\
5.56\end{array}$ & $\begin{array}{l}1.03 \\
1.12\end{array}$ & $\begin{array}{l}-0.83 \\
-0.91\end{array}$ & 0.73 & $\begin{array}{l}.619 / \\
.620\end{array}$ \\
\hline $\begin{array}{l}\text { PT: Relasjonell tillit til skole- } \\
\text { ledelsen (Bryk \& Schneider, } \\
\text { 2002) } \\
\text { Skolens ledelse har øye for den } \\
\text { personlige velferden til hver } \\
\text { enkelt lærer }\end{array}$ & w98 & 4.65 & 1.68 & -0.60 & -0.51 & $\begin{array}{l}.805 / \\
.807\end{array}$ \\
\hline $\begin{array}{l}\text { CL: Tydelig ledelse } \\
\text { Kommunikasjon med ledelsen } \\
\text { hjelper meg til å forstå hva som } \\
\text { forventes av meg }\end{array}$ & $\begin{array}{l}\text { w117 } \\
\text { w118 }\end{array}$ & $\begin{array}{l}4.59 \\
4.89\end{array}$ & $\begin{array}{l}1.46 \\
1.43\end{array}$ & $\begin{array}{l}-0.57 \\
-0.59\end{array}$ & $\begin{array}{l}0.04 \\
0.19\end{array}$ & $\begin{array}{l}.813 / \\
.814\end{array}$ \\
\hline
\end{tabular}

${ }^{1)}$ Reversert

Begrepet «Læreres kollegiale hjelpsomhet med IKT i undervisning» ble målt på en syv-punkts skala der ytterpunktene ble markert med: $1=$ Aldri, 7 = Svært ofte. De øvrige begrepene ble målt ved hjelp av en skala der $1=$ Helt uenig og 7 $=$ Helt enig.

Første steg i analysen var å studere sentraltendens, spredning, skjevhet, kurtose og Cronbachs alfa / Spearman-Brown-koeffisient. Med unntak av begrepet «Utviklingsorientert skolekultur» (som har et negativt ladet og et positivt ladet utsagn som kan ha skapt problemer), er alfa noenlunde tilfredsstillende sett i lys av at det er to indikatorer som brukes i hvert begrep (Crocker 
\& Algina, 1986). Tallverdien av kurtose er imidlertid noe høy for indikatorene w97 og w108.

Andre steg er å studere de bivariate korrelasjonene mellom de latente variablene (tabell 2). Det er disse assosiasjonene som er utgangspunktet for å estimere strukturmodellene.

Tabell 2. Bivariate korrelasjoner (Pearsons r) mellom latente variabler ${ }^{1)}$

\begin{tabular}{|c|c|c|c|c|c|}
\hline & TT & PT & CL & SCHD & OBC \\
\hline PT & .394 & & & & \\
\hline CL & .349 & .849 & & & \\
\hline SCHD & .287 & .537 & .550 & & \\
\hline OBC & .103 & .223 & .390 & .325 & \\
\hline REF & . 212 & .110 & .152 & -.037 & .251 \\
\hline
\end{tabular}

\section{Analysemåte}

Strukturell likningsmodellering - som passer for konfirmerende faktoranalyse og stianalyse - ble brukt for å analysere relasjonene mellom variablene. I vurderingen av tilpassing mellom modell og datasett ble følgende mål brukt: «root mean square error of approximation» (RMSEA), «non-normed fit index» (TLI), «goodness-of-fit index» (GFI) og «comparative fit index» (CFI). RMSEA $<0.05$ og TLI, GFI og CFI > 0.95 indikerer en god tilpassing, mens RMSEA < 0.08 og TLI, GFI og CFI $>0.90$ indikerer en akseptable tilpassing (Kline, 2005).

Både målemodellen og strukturmodellen ble estimert med IBM SPSS Amos 23. Ellipsene representerer de latente variablene. I vår teorimodell har vi vært nødt til å begrepsfeste noen begreper som eksogene og andre som endogene, men i våre tolkninger åpner vi opp for at relasjonene mellom begrepene kan være toveis. Når vi i figur 2 og 3 bruker stipiler, må dette forstås slik at stipilene på statistisk grunnlag predikerer den målte styrken i relasjonen uten at vi dermed kan si noe bestemt om kausalretning. Våre tolkninger knytter seg således til empiriske sammenhenger (relasjoner) og ikke kausalrelasjoner. Antallet respondenter er relativt lite, og derfor legger vi mer vekt på relasjoners styrke og substansbetraktninger enn signifikansbetraktninger. Vi understreker at våre funn bør legge et grunnlag for ytterligere validering og oppfølging. Styrken på relasjonene øker som kjent med stigende tallverdi på stikoeffisientene. Verdiene til RMSEA, TLI, GFI og CFI indikerer at strukturmodellen i figur 1 passer tilfredsstillende til data. 


\section{Resultater}

Figur 2 viser den første estimerte strukturmodellen. Vi har i flere ulike studier brukt disse begrepene, og begrepene tydelig ledelse og relasjonell tillit til skoleledere har hatt akseptabel diskriminerende validitet. I denne studien er korrelasjonen mellom tydelig ledelse og relasjonell tillit til skoleledere så høy som 0.85. Det betyr at disse to teoretisk belagte begrepene måler svært mye av det samme selv om vi kan skille mellom begrepene på teoretisk grunnlag. Altså, der hvor skolens mål er oppfattet på en tydelig måte, er det også høy relasjonell tillit og motsatt. En så sterk korrelasjon er et metodisk problem (fordi det antyder en viss lineær avhengighet), og vi velger derfor å utelate relasjonell tillit til skoleledere og estimere strukturmodellen på nytt: modell 2 i figur 3 blir derfor den modellen vi fester oss ved i det følgende. Dermed bortfaller noen av hypotesene i den etterpåfølgende drøftingen.
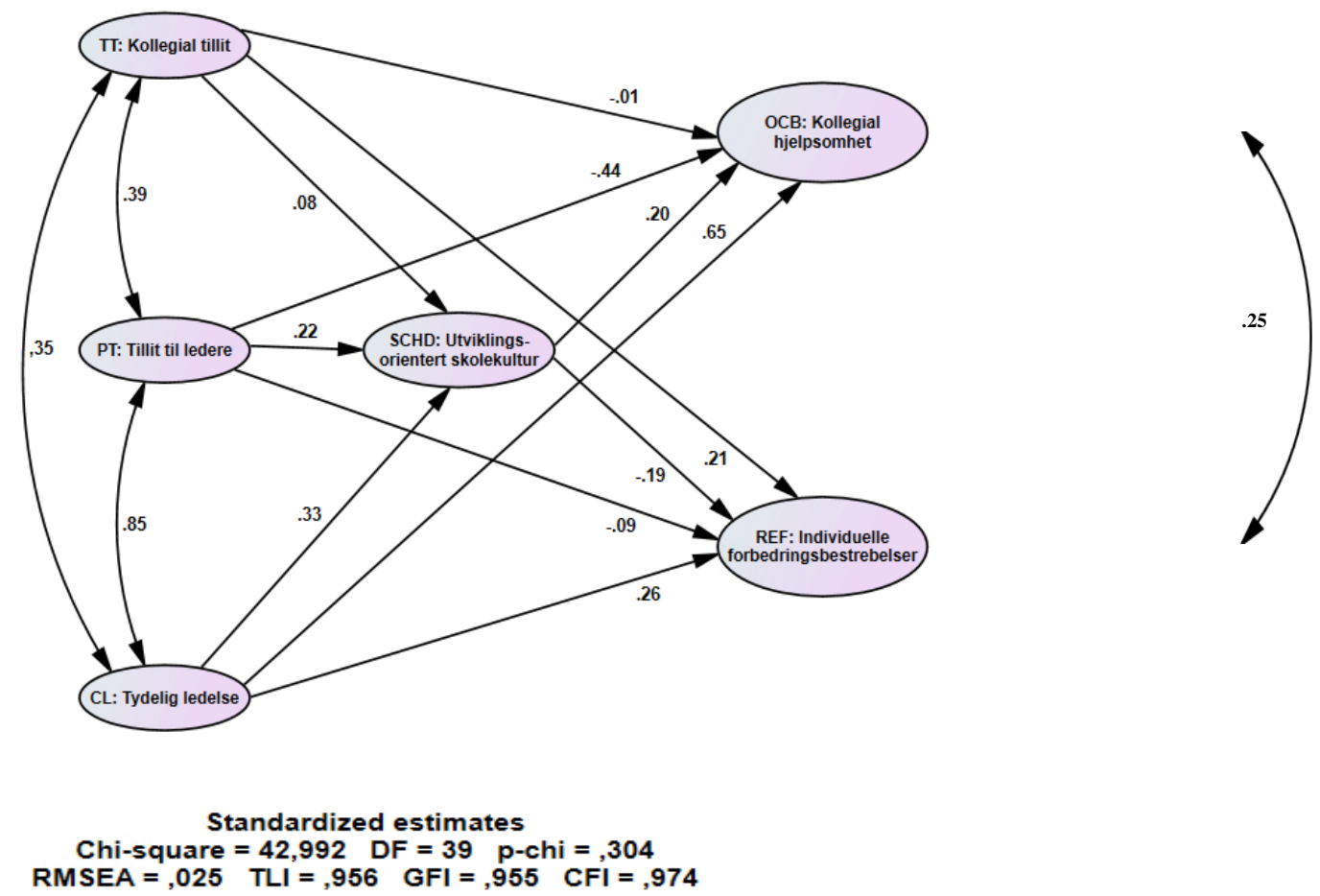

Figur 2. Strukturell likningsmodell nr. 1 som viser styrke i empiriske relasjoner mellom tydelig ledelse (CL), relasjonell tillit til skoleledere og lærere (PT), relasjonell tillit mellom lærere (TT), utviklingsorientert skolekultur (SCHD), kollegial hjelpsomhet (OCB) og individuelle forbedringsbestrebelser (REF). 

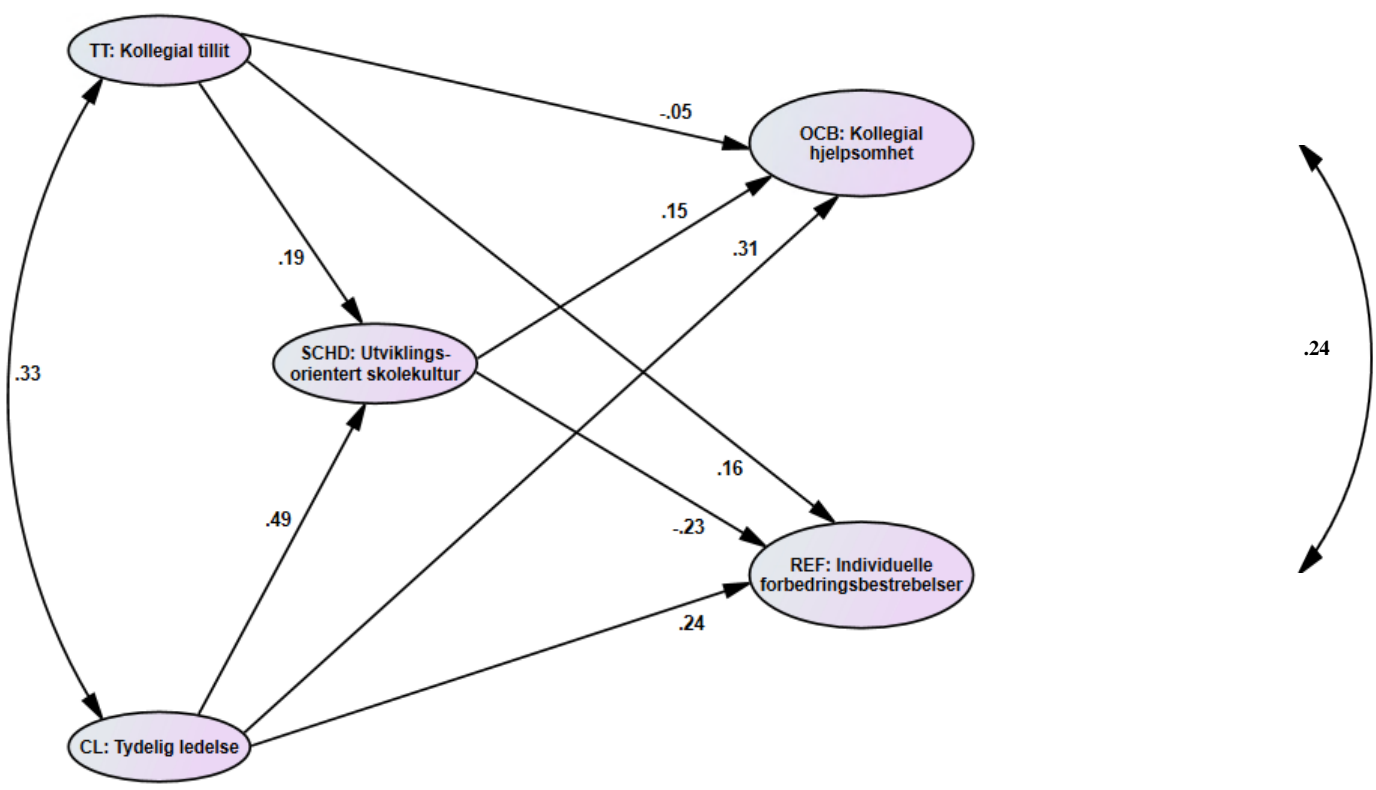

\section{Standardized estimates}

Chi-square $=26,276$ DF $=25$ p-chi $=, 393$

RMSEA $=, 018 \mathrm{TLI}=, 983 \mathrm{GFI}=, 967 \quad \mathrm{CFI}=, 991$

Figur 3. Strukturell likningsmodell nr. 2 som viser styrke i empiriske relasjoner mellom tydelig ledelse (CL), relasjonell tillit mellom lærere (TT), utviklingsorientert skolekultur (SCHD), kollegial hjelpsomhet (OCB) og individuelle forbedringsbestrebelser (REF).

Tabell 3. Oversikt: Konklusjonene på hypotesene i figur 1 basert på modellen i figur $3^{11}$.

\begin{tabular}{|c|c|c|}
\hline Hypotese & Ordlyd & Resultat \\
\hline 1 & $\begin{array}{l}\text { Tydelig ledelse }(C L) \text { er en faktor som er positivt } \\
\text { relatert til individuelle forbedringsbestrebelser } \\
(R E F) \text {. }\end{array}$ & $\begin{array}{l}\text { Det er en moderat relasjon mellom CL og REF, } \\
\text { men den er likevel ikke spesielt sterk: } \\
b(C L \rightarrow R E F)=.24 \text {. Hypotesen støttes. }\end{array}$ \\
\hline 2 & $\begin{array}{l}\text { Tydelig ledelse (CL) er en faktor som er positivt } \\
\text { relatert til kollegial hjelpsomhet (OCB). }\end{array}$ & $\begin{array}{l}\text { Det er en relasjon mellom tydelig ledelse og } \\
\text { OCB, og den er i moderat grad sterk: } \\
b(C L \rightarrow O C B)=.31 . \text { Hypotesen støttes. }\end{array}$ \\
\hline 3 & $\begin{array}{l}\text { Kollegial tillit (TT) er en faktor som er positivt } \\
\text { relatert til individuelle forbedringsbestrebelser } \\
(\mathrm{REF}) \text {. }\end{array}$ & $\begin{array}{l}\text { Det er en svak relasjon mellom TT og REF: } \\
b(T T \rightarrow R E F)=.16 . \text { Relasjonen er en tendens, } \\
\text { men hypotesen støttes ikke på en avklart måte. }\end{array}$ \\
\hline 4 & $\begin{array}{l}\text { Kollegial tillit (TT) er en faktor som er positivt } \\
\text { relatert til kollegial hjelpsomhet (OCB). }\end{array}$ & $\begin{array}{l}\text { Det er en meget svak og neglisjerbar relasjon } \\
\text { mellom TT og OCB: } b(T T \rightarrow O C B)=-.05 . \\
\text { Hypotesen støttes ikke. }\end{array}$ \\
\hline 7 & $\begin{array}{l}\text { Utviklingsorientert skolekultur (SCHD) er en } \\
\text { faktor som er positivt relatert til individuelle } \\
\text { forbedringsbestrebelser (REF). }\end{array}$ & $\begin{array}{l}\text { Det er en overraskende negativ relasjon mellom } \\
\text { SCHD og } R E F, \text { men den er ikke sterk: } \\
b(S C H D \rightarrow R E F)=-.23 \text {. Hypotesen støttes ikke. }\end{array}$ \\
\hline 8 & $\begin{array}{l}\text { Utviklingsorientert skolekultur (SCHD) er en } \\
\text { faktor som er positivt relatert til for kollegial } \\
\text { hjelpsomhet (OCB). }\end{array}$ & $\begin{array}{l}\text { Det er en svak relasjon mellom SCHD og OBC: } \\
b(S C H D \rightarrow O C B)=.15 \text {. Hypotesen støttes ikke } \\
\text { på en avklart måte. }\end{array}$ \\
\hline 9 & $\begin{array}{l}\text { Tydelig ledelse }(C L) \text { er en faktor som er positivt } \\
\text { relatert til utviklingsorientert skolekultur } \\
(S C H D) \text {. }\end{array}$ & $\begin{array}{l}\text { Det er en moderat sterk relasjon mellom } C L \text { og } \\
\text { SCHD: } b(C L \rightarrow S C H D)=.49 \text {. Hypotesen } \\
\text { støttes. }\end{array}$ \\
\hline 10 & $\begin{array}{l}\text { Kollegial tillit mellom larere (TT) er gunstig for } \\
\text { et utviklingsorientert skoleklima SCHD). }\end{array}$ & $\begin{array}{l}\text { Det er en moderat svak, men dog positiv } \\
\text { relasjon mellom kollegial tillit og utviklings- } \\
\text { orientert skolekultur: } b(T T \rightarrow S C H D)=.19 \text {. }\end{array}$ \\
\hline 13 & $\begin{array}{l}\text { Tydelig ledelse }(C L) \text { er positivt relatert til } \\
\text { kollegial tillit }(T T) \text {. }\end{array}$ & $\begin{array}{l}\text { Det er en moderat relasjon mellom } C L \text { og } T T \text { : } \\
b(C L \rightarrow T T)=.33 \text {. Hypotesen støttes. }\end{array}$ \\
\hline
\end{tabular}


Videre merker vi oss at relasjonen mellom tydelig ledelse (CL) og utviklingsorientert skolekultur er forholdsvis sterk: $\mathrm{b}(\mathrm{CL} \rightarrow \mathrm{SCHD})=.49$. Dette samsvarer med andre funn (Harris, Day, Hopkins, Hadfield, Hargreaves \& Chapman, 2013). Det er også en moderat relasjon mellom kollegial tillit (TT) og tydelig ledelse $(\mathrm{CL}): \mathrm{b}(\mathrm{CL} \rightarrow \mathrm{TT})=.33$. Dessuten merker vi oss en moderat svak, men dog positiv relasjon mellom kollegial tillit og utviklingsorientert skolekultur: $\mathrm{b}(\mathrm{TT} \rightarrow \mathrm{SCHD})=.19$.

\section{Diskusjon}

\section{Problemet med lineær avhengighet}

Når vi sammenlikner strukturmodell nr. 1 og 2, ser vi at de sammenliknbare stikoeffisientene i modell 2 har noenlunde samme tallverdi i de to modellene unntatt for den statistiske relasjonen mellom tydelig ledelse (CL) og kollegial hjelpsomhet (OCB). Forklaringen på dette fenomenet ligger $\mathrm{i}$ at tydelig ledelse (CL) og relasjonell tillit til skoleledere (PT) er sterkt assosiert. Dermed oppstår en lineær avhengighet mellom begrepene. Dette er overraskende fordi vi har analysert flere andre datasett fra grunnskolen der CL og PT bare i moderat grad har vært assosiert (Elstad, Christophersen \& Turmo, 2012). Ettersom stikoeffisenten mellom PT og CL er så høy som den er i dette tilfellet (.85), velger vi å fokusere på modell nr. 2 (figur 3) i denne drøftingen.

\section{En sentral slutning}

Modell nr. 2 gir empirisk belegg for å si at tydelig ledelse (CL) er en faktor som er relatert til kollegial hjelpsomhet med IKT i undervisning (OCB). Det er også tendenser til at tydelig ledelse er relatert til individuelle forbedringsbestrebelser (REF). Stikoeffisientene er imidlertid noe svakere enn for OCB. Med andre ord framstår tydelig kommunisert ledelse som en viktig faktor for ønskverdige intensjoner i den norske videregående skolen. En slutning vi tør trekke er at endringsprosesser i skolen er relatert til tydelig kommunisert lederskap. En implikasjon er at politikkutformere, skoleeiere og skoleledere som vektlegger kollegial hjelpsomhet i forbindelse med IKT-reformer i skolen eller individuelle forbedringsbestrebelser, kan vektlegge lederskap i skolen som er tydelig kommunisert. I dette spørsmålet er det antakelig et samspill mellom nasjonal utdanningspolitikk, eierpolitikk, skolelederskap og komplekse former for utøvd ledelse (Bush, 2008). Dette er et funn som også er i overensstemmelse med annen forskning på området, for eksempel Moolenaar, Daly og Sleegers (2010).

\section{Studiens svakheter}

Dette forskningsbidragets begrensninger må understekes: strengt tatt gir som nevnt ikke en tverrsnittsundersøkelse empirisk belegg for kausalslutninger (kan hende med unntak av sammenhenger mellom biologisk kjønn og variabler der 
genetikk er avgjørende). En tverrsnittstudie gir bare et øyeblikksbilde av empiriske sammenhenger. Skal vi komme nærmere et sikrere grunnlag for å kunne trekke kausalslutninger, trenger vi eksperimenter. Svært lite utdanningsforskning gjennomføres under slike premisser rett og slett fordi det er vanskelig å få dette gjennomført (Mertens, 2014). Også kvalitative oppfølgingsstudier kan gi oss verdifull empiri for å kunne gå bak tallene og tolke hva evidensgrunnlaget er godt for i lys av informantenes forståelse av situasjonen. «Mixed methods» er her en interessant tilnærming (Hesse-Biber \& Johnson, 2013). Operasjonaliseringen av variablene er basert på to indikatorer. En styrking av begrepsvaliditeten ved å inkludere flere spørsmål som har gode psykometriske egenskaper, kan være gunstig for oppfølging av studien. Reliabiliteten for vårt mål for skolekultur og kollegial hjelpsomhet kan også forbedres. Studiens svakheter bør med andre ord møtes med bedre forskningsinstrumenter.

En annen begrensning gjelder utvalget. Vi mener resultatene i denne studien har en viss gyldighet for skoler som har liknende attributter som de skolene som inngår i utvalget. Det er et åpent spørsmål om de funn vi har påvist har gyldighet for videregående skoler som tar inn elever fra det høyeste og det laveste sjiktet av inntakspoeng. Tidligere forskning har kunnet påvise seleksjonseffekter i læreres valg av arbeidssted (Bonesrønning, Falch \& Strøm, 2005). Seleksjonseffekter kan derfor influere på validitetsgrunnlaget, men kan hende gjelder dette først og fremst de mest attraktive skolene. A styrke den eksterne validiteten for denne forskningstilnærmingen vil være en naturlig videreføring av denne studien.

De tre skolene som inngår i utvalget, har klare strukturelle likhetstrekk og har likhetstrekk når det gjelder gjennomsnittlig prestasjonsnivå og skolens bidrag til elevers læringsframgang. Men det vil normalt sett være forskjeller mellom skoler, for eksempel i hvordan lederskap utøves. I vår studie sviktet denne markøren i innleggingen av dataene fra de papirbaserte spørreskjemaene til datafil, slik at vi mistet muligheten til å gjennomføre flernivåanalyse. Dette gir også en begrensning som bør følges opp. I framtidig forskning vil det derfor være viktig å korrigere for den delen av variasjonen som tilskrives det at informantene tilhører ulike grupper.

\section{Lærersamarbeid - en utfordring i videregående skoles arbeidskultur?}

Lærersamarbeid er ofte omtalt som en viktig satsing for skoleeiere (KS, 2015). Forskning gir i noen grad et belegg for troen på at lærersamarbeid er gunstig for å forbedre skoler (Daly, Moolenaar, Bolivar \& Burke, 2010; Moolenaar, 2012). Med en slik forventning byr analysen av relasjoner mellom utviklingsorientert skolekultur og individuelle forbedringsbestrebelser på et overraskende funn: det er en svak, men negativ relasjon mellom utviklingsorientert skolekultur og individuelle forbedringsbestrebelser. Dette funnet bør følges opp i videre forskning. Flere alternative forklaringer er mulige. Andy Hargreaves (1996) snakker om skoleforbedringstiltak som ikke nødvendigvis fenger lærere og som kan opp- 
leves som påtvungen kollegialitet: pedagogiske trender og ideer kommer og går, og lærere kan oppleve avstand mellom luftige visjoner og det som er faktisk gjennomførbart i den praktiske undervisningshverdagen. Dermed kan det oppleves et skott mellom de pedagogisk korrekte og fantasifulle ideene forfattet ved et skrivebord og det lærere opplever som reelle utfordringer i den praktiske undervisningshverdagen. Geert Kelchtermans’ oppsummering av forskning på feltet (2006) viser at lærersamarbeid kan være utfordrende. Skal lærersamarbeid bli en vellykket strategi i videregående skoler, er det viktig å få lærerne med på laget. En mulig implikasjon kan være at forhandlinger om ønskverdige endringsprosesser i skolen skjer på en slik måte at lærere føler eierskap i de endringsprosessene som ledere, skoleeiere og nasjonale myndigheter iverksetter (Nygård \& Røvik, 2014).

Nyinstitusjonell teori betoner at skoleledere - i en situasjon der ytre omgivelser uttrykker reformforventninger - kan beskytte sine ansatte ved å håndtere de ytre forventningene som myndighetene har, slik at lærerne får konsentrere seg om det som er viktig: effektiv undervisning som fører til målbare resultater når det gjelder elevers læring (Meyer \& Rowan, 1977; Røvik, 2014). De ytre, pedagogisk-korrekte trendene blir i lys av dette fenomenet «dekoplet» fra skolens kjernevirksomhet: det blir et gap mellom bildet av skolen utad - som lojal overfor de ønskverdige styringssignaler som gis - og den faktiske praksis som i lys av dette noe nedlatende kalles «tradisjonelle undervisningsmetoder» (Opheim, Grøgaard \& Næss, 2010). Meyer og Rowan (1977) kaller dette fenomenet rasjonaliserte institusjonelle myter. Lærerautonomi gir handlingsrom for å «overleve» i utviklingsorienterte miljøer som en del lærere kan ha begrenset sans for. Lærere i videregående skole har vanligvis sitt virke i hvert sitt klasserom uten regulær kollegial kontakt mens undervisning pågår (Lortie, 1975). Den enkeltes innsats for å forbedre sin undervisning er normalt sett ikke observerbar for kollegaer, og vi har heller ingen tradisjon i Norge for transparens om for eksempel målinger av den enkelte lærers bidrag til elevers læringsframgang. Dermed vil det å holde igjen på sin egen forbedringsinnsats i en utviklingsorientert skolekultur som preges av stadig pågående endringsprosesser, ikke nødvendigvis rammes av sosiale normer på arbeidsplassen; man kan rett og slett slippe å yte i kollektiv utvikling av digitale læringsressurser dersom kollegaer står på, og motsatt (Latané, Williams \& Harkins, 1979; Kelchtermans, 2006). Dette kan sammenliknes med å trykke svakt på pedalene når man sykler med tandemsykkel i håp om at makkeren anstrenger seg (Kerr, 1983).

Individuelle forbedringsbestrebelser omfatter tilbøyelighet til å snappe opp gode eksempler fra andre lærere og bruke disse ideene i egen undervisning. Dette er en kompenserende antakelse basert på fortolkning av en empirisk regularitet i vårt materiale: der hvor den utviklingsorienterte skolekulturen er sterk, er det en tendens til at lærere foretrekker lav intensitet i egne forbedringsbestrebelser (og motsatt). Dette kan ha noe med at utviklingsorienterte skoleprosjekter som er skolepolitisk korrekte, tapper en begrenset menneske- 
ressurs (Job, Dweck \& Walton, 2010). Vi konstaterer dette funnet og understreker at det bør utforskes i videre forskning i håp om å styrke validiteten eller forkaste antakelsen.

Studier av læreres tidsbruk i grunnskolen viser høy tidsbruk i jobbsammenheng (Tidsbrukutvalget, 2009), mens andre studier dokumenterer at lærere over tid kan være utsatt for utbrenthet (Skaalvik \& Skaalvik, 2007). Vi kjenner ikke til tilsvarende undersøkelser fra videregående skole. Det må som nevnt også understrekes at det forholdsvis lave antallet lærere utvalget består av, er hentet fra skoler som plasserer seg i midtsjiktet når det gjelder inntakspoeng og skolens bidrag til elevers læringsframgang. Et ubesvart spørsmål er om de regulariteter vi har funnet, har gyldighet for skoler som plasserer seg i det øvre og det laveste sjiktet av henholdsvis inntakspoeng og bidrag til læringsframgang. Også dette er noe som bør forfølges i framtidig forskning. Det kan i denne sammenheng også være interessant å studere nærmere skoler som i spesiell grad er utviklingsorientert. Det kan her vises til skifter i entusiasme i ulike faser av skoleutviklingsprosjekter (Elstad, 2016c). Med andre ord tror vi at relasjonen mellom skoleutvikling og læreres innstillinger er kontekstavhengig. Hvis det er riktig, tilsier det varsomhet i generaliserte slutninger basert på denne typen empirisk forskning.

\section{Kollegial hjelpsomhet og læreres profesjonelle vekst}

Undervisningens hensikt er at elever skal lære. Imidlertid har det ikke vært mulig å kople våre survey-data med datasett som inkluderer læreres faktiske bidrag til elevers læringsframgang (målt gjennom elevprestasjoner på to ulike tidspunkter). Denne typen forskning er krevende å realisere i Norge gitt de lovregler som finnes for å sikre anonymitet i forskning. Men det finnes internasjonal forskning som gir empirisk belegg for at høy grad av «organizational citizenship behavior» (OCB) er gunstig for læreres profesjonelle vekst (Bogler \& Somech, 2004) og for elevprestasjoner i skolen (DiPaola \& Hoy, 2005). Sammenhengene kan imidlertid anses å være komplekse. Blant annet bidrar styrket lærerprofesjonalitet til bedre læringsresultater i de første 6-8 årene i lærerkarrieren for deretter å flate ut (ja, sågar synke noe etter flere års erfaring, Rockoff, 2004; Rivkin, Hanushek \& Kain, 2005). Annen forskning gir empirisk belegg for å understreke kontekstens sentrale betydning for læreres profesjonelle vekst (Kraft \& Papay, 2014). Målinger av forbedringsbestrebelser gjennom læreres karrierer kjenner vi ikke til, men en mulig antakelse er at innsatsen er høy de første årene inntil læreren utvikler et undervisningsrepertoar som viser seg å fungere. Når en lærer utvikler et undervisningsrepertoar som fungerer, kan noen lærere dempe intensiteten i forbedringsbestrebelser, og en etablert og fungerende praksis kan feste seg som en mer eller mindre varig praksis (Huberman, Grounauer \& Marti, 1993). Men det er også mulig at endringsinnsatsen holdes ved like. Det empiriske grunnlaget for å anta det førstnevnte er at lærernes mestringsforventninger til det å undervise øker 
gjennom de første årene for så å avta senere i yrkeskarrieren (Klassen \& Chiu, 2010). Vi vet rett og slett for lite om hvordan økt satsing på å utvikle digitale læringsressurser og annen IKT-støttet undervisning faktisk bidrar til læringsframgang. Dette er en utfordring for framtidig forskning, og her kreves longitudinelle forskningstilnærminger.

\section{Organisatoriske faktorer og undervisningsteknologiens muligheter og begrensninger}

Vi finner grunn til å anta at kvaliteten på digitale læringsressurser har betydning for lærerens vurdering av om de er egnet, og ikke mengden av bruk av digitale læringsressurser (Elstad, 2016a). Med andre ord avhenger teknologiens lykksalige effekter av en rekke forhold som må være til stede for at IKT skal ha gunstig innvirkning på elevers læringsprosesser. En implikasjon for lærernes arbeid er at det er teknologiens rasjonale som teller, og ikke det at teknologi for enhver pris må brukes i skolen (Biesta, 2016; Salomon, 2016). Den viktige empiriske begrunnelsen for denne antakelsen er en komparativ makrostudie i regi av OECD som viser et kurvi-lineært forløp mellom omfang på IKTanvendte læringsressurser og prestasjonsutvikling (OECD, 2015). Imidlertid viser analyser at noen spesifikke IKT-anvendelser kan gi bedre læring (for eksempel Zacharia \& de Jong, 2014). Dette gjelder virkninger i komplekse samspill mellom lærer, kunnskapsrepresentasjoner gjennom læremidler og elever. Det studieobjektet vi fokuserer på i denne artikkelen, gjelder derimot organisasjonsmessige faktorer som er relatert til læreres profesjonelle utvikling, enten gjennom individuelle bestrebelser eller via kollegial hjelpsomhet. Den negative relasjonen vi fant mellom utviklingsorientert skolekultur og læreres individuelle forbedringsbestrebelser, kan forstås i et slikt perspektiv. Forskningen om sammenhenger mellom skolekultur og læreres profesjonelle vekst er bare i startgropa (Avalos, 2011), og vi forventer mer interesse og utforskning av hva slags faktorer som er viktige i skoleforbedringsarbeidet i framtiden.

Relasjonen mellom utviklingsorientert skolekultur og kollegial hjelpsomhet er nokså svak, men dog positiv. Dette er i samsvar med våre forventninger som er basert på tidligere forskning (DiPaola \& Tschannen-Moran, 2014). Den positive, men svake relasjonen kan tyde på at den kollegiale bestrebelsen ikke har en klar sammenheng med det som skjer på individuell basis. Med andre ord er vår tolkning at det kan være mentale skott mellom kollektive og individuelle prosesser, noe som igjen impliserer at vi trenger mer forskning om det komplekse forholdet mellom skolekultur og kollegial hjelpsomhet når det gjelder å iverksette teknologiske innovasjoner i skolen.

Det er også svake empiriske relasjoner mellom kollegial relasjonell tillit (TT) og utviklingsorientert skolekultur (SCHD), og mellom kollegial tillit (TT) og kollegial hjelpsomhet (OCB) og individuelle forbedringsbestrebelser (REF). Dette avviker noe fra forskning fra amerikanske grunnskoler der den relasjonelle tilliten framstod som smøreolje i skolens komplekse maskineri, noe som igjen ga 
grunnlag for momentum i skoleutviklingsprosjekter gjennom tydelig lederskap (Bryk \& Schneider, 2002). Det kan være at samarbeidskulturen i norske videregående skoler av det slaget vi har studert, er noe forskjellig fra kulturen i grunnskoler, og det kan være andre kontekstuelle forskjeller som er av betydning. Nok en gang må vi understreke behovet for mer forskning og gjerne med utvalg som også omfatter skoler som er både mer og mindre utviklingsorienterte enn de som vi har med i vårt utvalg. Utvalg som bidrar til økt varians vil kunne gi oss bedre slutningsmuligheter når det gjelder empiriske assosiasjoner mellom begreper. Vi vet heller ikke om kollegial hjelpsomhet knyttet til IKT i undervisning skiller seg fra kollegial hjelpsomhet som ikke har noe spesifikt med IKT i undervisning å gjøre. Dette er også et tema for videre forskning.

\section{Takk}

Denne studien er finansiert av midler fra Norges forskningsråd (bevilgning nr. 218245) og er en del av forskningsprosjektet Learning in the 21st century. Forfatterne takker tidsskriftets korrekturleser to fagfellevurderere for deres konstruktive kommentarer.

\section{Om forfatterne}

Eyvind Elstad er professor ved Institutt for lærerutdanning og skoleforskning, Universitetet i Oslo. Hans forskningsinteresser omfatter blant annet læreres arbeid, lærerutdanning og IKT i skolen.

Institusjonstilknytning: Institutt for lærerutdanning og skoleforskning, Universitetet i Oslo, Niels Henrik Abels hus, Moltke Moes vei 35, 0851 OSLO.

E-post: eyvind.elstad@ils.uio.no

Knut-Andreas Christophersen er pensjonert førsteamanuensis ved Institutt for statsvitenskap, Universitetet i Oslo. Hans forskningsinteresse er i særlig grad forskningsmetodiske spørsmål.

Institusjonstilknytning: Institutt for statsvitenskap, Universitetet i Oslo, Eilert Sundts hus, Moltke Moes vei 31, 0851 OSLO.

E-post: k.a.christophersen@stv.uio.no 


\section{Referanser}

Avalos, B. (2011). Teacher professional development in Teaching and Teacher Education over ten years. Teaching and Teacher Education, 27(1), 10-20.

Belogolovsky, E. \& Somech, A. (2010). Teachers' organizational citizenship behavior: Examining the boundary between in-role behavior and extra-role behavior from the perspective of teachers, principals and parents. Teaching and Teacher Education, 26(4), 914-923.

Biesta, G. (2016). ICT and Education Beyond Learning: A Framework for Analysis. I E. Elstad (red.), Digital expectations and experiences in education (s. 29-43). Rotterdam: Sense Publishers.

Bogler, R. \& Somech, A. (2004). Influence of teacher empowerment on teachers' organizational commitment, professional commitment and organizational citizenship behavior in schools. Teaching and Teacher Education, 20(3), 277-289.

Bonesrønning, H., Falch, T. \& Strøm, B. (2005). Teacher sorting, teacher quality, and student composition. European Economic Review, 49(2), 457-483.

Bryk, A. S. \& Schneider, B. (2002). Trust in Schools: A Core Resource for Improvement. New York: The Russell Sage Foundation.

Bryk, A. S. (2010). Organizing schools for improvement. Phi Delta Kappan, 91(7), 23-30.

Bush, T. (2008). Leadership and management development in education. New York: Sage.

Christ, O., Dick, R., Wagner, U. \& Stellmacher, J. (2003). When teachers go the extra mile: Foci of organisational identification as determinants of different forms of organisational citizenship behaviour among schoolteachers. British Journal of Educational Psychology, 73(3), 329-341.

Crocker, L. \& Algina, J. (1986). Introduction to classical and modern test theory. Toronto: Holt, Rinehart and Winston Inc.

Daly, A. J., Moolenaar, N. M., Bolivar, J. M. \& Burke, P. (2010). Relationships in reform: The role of teachers' social networks. Journal of Educational Administration, 48(3), 359391.

de Vries, S., Jansen, E. P. \& van de Grift, W. J. (2013). Profiling teachers' continuing professional development and the relation with their beliefs about learning and teaching. Teaching and Teacher Education, 33, 78-89.

DiPaola, M. F. \& Hoy, W. K. (2005). Organizational citizenship of faculty and achievement of high school students. The High School Journal, 88(3), 35-44.

DiPaola, M. \& Tschannen-Moran, M. (2014). Organizational citizenship behavior in schools and its relationship to school climate. Journal of School Leadership, 11(5), 424-447.

Elstad, E. (2016a). Educational technology: expectations and experiences. An introductory overview. I E. Elstad (red.), Digital expectations and experiences in education (s. 3-28). Rotterdam: Sense Publishers.

Elstad, E. (2016b). Educational technology in schools. Policymaking and policy enactment. I E. Elstad (red.), Digital expectations and experiences in education (s. 48-57). Rotterdam: Sense Publishers.

Elstad, E. (2016c). Why is there a wedge between the promise of educational technology and the experiences of a technology-rich pioneer school? I E. Elstad (red.). Digital expectations and experiences in education (s. 77-96). Rotterdam: Sense Publishers.

Elstad, E., Christophersen, K.-A. \& Turmo, A. (2011). Social Exchange Theory as Explanation of Teacher Organizational Citizenship Behavior. International Journal of Leadership in Education, 14 (4), 405-422. 
Elstad, E., Christophersen, K.-A. \& Turmo, A. (2012). The strength of accountability and teachers' organizational citizenship behaviour. Journal of Educational Administration, 50 (5), 612-628.

Falch, T., Bensnes, S. \& Strøm, B. (2016). Skolekvalitet i videregående opplaring. Utarbeidelse av skolebidragsindikatorer og mål på skolekvalitet. Trondheim: Senter for økonomisk forskning.

Hargreaves, A. (1996). Lererarbeid og skolekultur. Lœreryrkets forandring i en postmoderne tidsalder. Oslo: Gyldendal.

Hargreaves, D. H. (1995). School culture, school effectiveness and school improvement. School Effectiveness and School Improvement, 6(1), 23-46.

Harris, A., Day, C., Hopkins, D., Hadfield, M., Hargreaves, A. \& Chapman, C. (2013). Effective leadership for school improvement. London: Routledge.

Hauge, T. E. \& Lund, A. (2012). Små skritt eller store sprang? Om digitale tilstander i skolen. Oslo: Cappelen Damm Akademisk.

Hesse-Biber, S. \& Johnson, R. B. (2013). Coming at things differently: future directions of possible engagement with mixed methods research. Journal of Mixed Methods Research, 7(2), 103-109.

Huberman, A. M., Grounauer, M. M. \& Marti, J. (1993). The lives of teachers. London: Cassell.

Huberman, A. M. \& Miles, M. B. (2013). Innovation up close: How school improvement works. Dordrecht: Springer Science \& Business Media.

Job, V., Dweck, C. S. \& Walton, G. M. (2010). Ego depletion-Is it all in your head? Implicit theories about willpower affect self-regulation. Psychological Science, 21(11), 16861693.

Kelchtermans, G. (2006). Teacher collaboration and collegiality as workplace conditions. A review. Zeitschrift für Pädagogik, 52(2), 220-237.

Kerr, N. (1983). The dispensability of member effort and group motivation losses: free-rider effects. Journal of Personality and Social Psychology, 44, 78-94.

Klassen, R. M. \& Chiu, M. M. (2010). Effects on teachers' self-efficacy and job satisfaction: Teacher gender, years of experience, and job stress. Journal of Educational Psychology, 102(3), 741-756.

Kline, R. B. (2005). Principle and practice of structural equation modeling. New York: The Guildford Press.

Kraft, M. A. \& Papay, J. P. (2014). Can professional environments in schools promote teacher development? Explaining heterogeneity in returns to teaching experience. Educational Evaluation and Policy Analysis, 36(4), 476-500.

KS (2015). KS' eierstrategi for barnehage og skole 2013-2016. Oslo: KS.

Kunnskapsdepartementet (2014). Lœrerløftet. På lag med kunnskapsskolen. Oslo: Kunnskapsdepartementet.

Kuvaas, B. \& Dysvik, A. (2016). Lønnsomhet gjennom menneskelige ressurser (3. utgave). Bergen: Fagbokforlaget.

Latané, B., Williams, K. \& Harkins, S. (1979). Many hands make light the work: the causes and consequences of social loafing. Journal of Personality and Social Psychology, 37, 822-832.

Leithwood, K. A. \& Riehl, C. (2003). What we know about successful school leadership. Nottingham: National College for School Leadership.

LePine, J. A., Erez, A. \& Johnson, D. E. (2002). The nature and dimensionality of organizational citizenship behavior: a critical review and meta-analysis. Journal of Applied Psychology, 87(1), 52-65.

Lortie, D. C. (1975). Schoolteacher. Chicago: The University of Chicago Press. 
Mertens, D. M. (2014). Research and evaluation in education and psychology: Integrating diversity with quantitative, qualitative, and mixed methods. New York: Sage Publications.

Meyer, J. W. \& Rowan, B. (1977). Institutionalized organizations: Formal structure as myth and ceremony. American Journal of Sociology, 83(2), 340-363.

Moolenaar, N. M., Daly, A. J. \& Sleegers, P. J. (2010). Occupying the principal position: Examining relationships between transformational leadership, social network position, and schools' innovative climate. Educational Administration Quarterly, 46(5), 623-670.

Moolenaar, N. M. \& Sleegers, P. J. (2010). Social networks, trust, and innovation. How social relationships support trust and innovative climates in Dutch Schools. I A. Daly (red.), Social Network Theory and Educational Change (s. 1-26). Cambridge, MA: Harvard University Press.

Moolenaar, N. M., Daly, A. J. \& Sleegers, P. J. (2011). Ties with potential: Social network structure and innovative climate in Dutch schools. Teachers College Record, 113(9), 1983-2017.

Moolenaar, N. M. (2012). A social network perspective on teacher collaboration in schools: Theory, methodology, and applications. American Journal of Education, 119(1), 7-39.

Nygård, S. R. \& Røvik, K. A. (2014). Hit, men ikke lenger. Når Lean skal løftes inn i klasserommet. I K. A. Røvik, T. V. Eilertsen \& E. M. Furu (red.), Reformideer i norsk skole. Spredning, oversettelse og implementering (s. 307-333). Oslo: Cappelen Damm Akademisk.

OECD (2015). Students, Computers and Learning. Making the Connection, Paris: OECD.

Opheim,V., Grøgaard, J. B. \& Næss, T. (2010). De gamle er eldst? Betydning av skoleressurser, undervisningsformer og læeringsmiljø for elevenes prestasjoner på femte, åttende og tiende trinn i grunnopplcringen. Oslo: NIFU STEP.

Organ, D. W. (1988). Organizational citizenship behavior: The good soldier syndrome. New York: Lexington Books.

Rivkin, S. G., Hanushek, E. A. \& Kain, J. F. (2005). Teachers, schools, and academic achievement. Econometrica, 73(2), 417-458.

Robinson, V. M., Lloyd, C. A. \& Rowe, K. J. (2008). The impact of leadership on student outcomes: An analysis of the differential effects of leadership types. Educational Administration Quarterly, 44(5), 635-674.

Rockoff, J. E. (2004). The impact of individual teachers on student achievement: Evidence from panel data. The American Economic Review, 94(2), 247-252.

Røvik, K. A. (2014). Translasjon - en alternativ doktrine for implementering. I K. A. Røvik, T. V. Eilertsen \& E. M. Furu (red.), Reformideer i norsk skole. Spredning, oversettelse og implementering (s. 403-418). Oslo: Cappelen Damm Akademisk.

Salomon, G. (2016). It's Not Just the Tool but the Educational Rationale That Counts. I E. Elstad (red.), Educational technology and polycontextual bridging (s. 149-161). Rotterdam: Sense Publishers.

Skaalvik, E. M. \& Skaalvik, S. (2007). Dimensions of teacher self-efficacy and relations with strain factors, perceived collective teacher efficacy, and teacher burnout. Journal of Educational Psychology, 99(3), 611-625.

Tidsbrukutvalget (2009). Rapport fra Tidsbrukutvalget. Nedlastet 21. mai 2016 fra https://www.regjeringen.no/globalassets/upload/KD/Vedlegg/Grunnskole/Tidsbrukutvalg et/Rapport_Tidsbrukutvalget.pdf

Tschannen-Moran, M. (2014). Trust Matters: Leadership for Successful Schools. San Francisco: Jossey-Bass.

Turmo, A., Elstad, E. \& Christophersen, K.-A. (2013). Organisational antecedents of teachers' perceived time capacity to energise effort: A Norwegian study. Education Inquiry, 4(2), 335-353. 
Zacharia, Z. C. \& de Jong, T. (2014). The effects on students' conceptual understanding of electric circuits of introducing virtual manipulatives within a physical manipulativesoriented curriculum. Cognition and Instruction, 32(2), 101-158.

Zeinabadi, H. \& Salehi, K. (2011). Role of procedural justice, trust, job satisfaction, and organizational commitment in Organizational Citizenship Behavior (OCB) of teachers: Proposing a modified social exchange model. Procedia - Social and Behavioral Sciences, 29, 1472-1481.

\footnotetext{
${ }^{1}$ Datasettet består av svar fra 159 lærere. Noen få lærere hadde unnlatt å svare på én eller flere av indikatorene i spørreskjemaet. Disse lærerne har vi ikke tatt med i analysen.
} 